\title{
The assessment of practical teaching quality in the major of civil engineering based on ability standard
}

\author{
Chunping Tang ${ }^{1, a^{*}}$, Jian Liu ${ }^{2, b}$ \\ ${ }^{1}$ Chongqing Technology and Business Institute, Chongqing 400052, Chongqing, China \\ ${ }^{2}$ Chongqing Technology and Business Institute, Chongqing 400052, Chongqing, China \\ atcp501@163.com, ${ }^{b} 635629601 @ q q . c o m$
}

Keywords: higher vocational education; teaching quality; assessment index; assessment standard

\begin{abstract}
Based on the professional ability of civil engineering majors, this research investigates the issues concerning the construction of systems for evaluating practical teaching quality by performing exploratory factor analysis. This study is conducted based on the principles of being scientific, systematic, feasible, and diverse. Besides, the authors construct an index system for evaluating the practical teaching quality, which has been proven to be applicable to higher vocational colleges (HVCs). The system involves the assessments of the background, input, process, and achievements of practical teaching. It aims to provide a basis for the supervision of the practical teaching quality in HVCs.
\end{abstract}

\section{Introduction}

The evaluation of practical teaching quality, as a systematic project, involves demands of multiple interest subjects. At present, a set of quality evaluation system that is scientific, practicable and universally applicable has not been established[1]. Therefore, the method for constantly improving the evaluation system for practical teaching quality according to the characteristics of higher vocational education (HVE) is the key to the expansion and quality improvement of higher vocational colleges (HVCs). It is also the primary task of each HVC that needs to be paid more attentions[2]. While highlighting the quality of practical teaching and the improvement of teaching efficiency, HVCs do not have a scientific and systematic quality evaluation system for practical teaching. This prominent contrast calls for the establishment of a set of scientific evaluation system for practical teaching quality as soon as possible.

Starting from the critical step in the evaluation system for practical teaching quality, this research attempts to provide a general rule through analysis and summary. The general rule is expected to serve as a reference for the establishment of the evaluation system. Based on this, this research constructs an evaluation system for the class teaching of HVCs, which contributes to the teaching management of HVCs. This study also explores the optimal approach for the evaluation and feedback of teaching quality, so as to provide a feasible plan for total quality management of HVE. The plan can be utilized as a reference for managing the teaching quality of HVCs.

\section{Objective and significance of constructing the evaluation system for practical teaching quality}

The objective of talent cultivation of HVCs is to cultivate technology applied and skilled talents. Students' technology application ability and professional skills can only be achieved by practical teaching. The establishment of the system for evaluating the quality of practical teaching is a key point in the evaluation of practical teaching quality for civil engineering majors. HVCs aim to cultivate talents who are able to meet social demands. To realize this purpose, one of countermeasures is to construct a scientific and effective evaluation system for practical teaching[3]. The construction of the teaching quality evaluation system is conducive to enhancing the quality of practical teaching and establishing a competitive and incentive mechanism. Besides, it is expected to improve teachers' teaching methods and levels, and promote the reform and management of practical 
teaching. In this way, cultivation qualities are improved, therefore enhancing students' competitive advantages.

\section{Fundamental principles in constructing the evaluation system}

Civil engineering is a specialty calls for a great deal of practice. For applied talents, they are trained to acquire professional skills. Thus, practical teaching needs to be paid much attention in teaching process. For the practical teaching, its content, form, and management of each link should be detailed, so as to make the teaching highly operable. In the research, according to the construction of the mechanism for supervising practical teaching quality in our school, four principles are proposed for constructing the quality index system. The four principles are scientificity and feasibility, practicability, systematicness, and diversity. According to these principles, each index needs to be proposed after scientific appraisal while setting evaluation indexes, so as to make it present a scientific basis and reflect quality characteristics of practice teaching directly[4]. On the premise of showing the evaluation objective, the evaluation system constructed requires to be as simple as possible. In addition, the evaluation system needs to clarify the objective and comprehensively design the evolution principles and elements. The evaluation system is supposed to be systemic and independent, with comparable factors. Moreover, evaluation indexes require to show explicit definitions and the evaluation standard has to be objective and comprehensive, and accord with overall goals of practical teaching.

\section{Matters need attention in constructing the evaluation system}

On the basis of scientificity, the evaluation system established should be simple and easy to perform. While determining the factors and indexes weights for evaluating practical teaching quality, both universalities and individualities of practical teaching of HVCs need to be considered. As the evaluation system for practical teaching quality of civil engineering majors is a general standard, the relations between generality and specialty are supposed to be handled correctly. For the overall evaluation of practical teaching quality, apart from objective standards like evaluation indexes, other factors should be considered comprehensively as well. These factors include students' qualities, curriculum design, practical training projects and the specific conditions of practice organizations. Besides, while determining index weights, the influencing degrees of all factors on the teaching quality need to be sufficiently considered.

\section{Assessment of practical teaching quality of HVCs}

The evaluation of practical teaching quality is a complex issue due to the complexity of practical teaching system. The teaching system is influenced by various factors including internal and external factors, as well as subjective and objective ones. These factors are related to and mutually restricted by each other. Hence, whether the expected results are achieved or not in the design and implementation of practical teaching needs to be checked while designing the evaluation system for practical teaching quality[5]. This can be realized by improving the professional practical teaching based on the quality control system.

This paper adopts the assessment table of weighting factors to determine weights of first grade indexes. The importance of all the indexes is identified through pairwise comparison. Because weights of indexes directly influence the evaluation result of practical teaching quality of HVCs, the assessment table of weighting factors is adopted to perform pairwise comparison for each index designed. Then, the weights can be determined by assessing the scores of each factor. The implementation steps are as follows: First is to form an expert team composed of experts from various fields and related personnel. The composition of the expert team can be varied according to evaluation objects and purposes. Second, an assessment table of weighting factors needs to be formulated. Third, the experts fill in the assessment table by comparing the factors in each row and 
column. If a four-point system is adopted, the extremely important, very important, important, less important, and unimportant indexes are marked with 4, 3, 2, 1, and 0 scores, respectively. Four, the assessment table of weighting factors filled by the experts are analyzed statistically.

(1) Calculating score values of evaluation indexes in each row according to the following formula:

$$
D_{i R}=\sum_{\substack{i=1 \\ j=i}}^{n} \alpha_{i j}
$$

Where $\mathrm{N}$ is the number of terms of evaluation indexes, $\alpha_{i j}$ represents the score value obtained through comparison between evaluation indexes $\mathrm{i}$ and $\mathrm{j}$, and $\mathrm{R}$ denotes the serial number of experts.

(2) Calculating average score values of evaluation indexes according to the formula below:

$$
p_{i}=\sum_{R=1}^{L} \frac{D_{i R}}{L}
$$

Where, $L$ represents the number of experts.

(3) Computing the weights of evaluation indexes using

$$
W_{i}=\frac{p_{i}}{\sum_{i=1}^{n} p_{i}}
$$

In this paper, the assessment table of weighting factors is employed to determine the weights of the indexes. The weights need to be assigned rationally through review and discussion of experts.

Table 1 The assessment of weighting factors

\begin{tabular}{|c|c|c|c|c|c|c|}
\hline \multirow{2}{*}{$\begin{array}{c}\text { Index } \\
\text { No. }\end{array}$} & \multirow{2}{*}{$\begin{array}{c}\text { Assessment } \\
\text { indexes for } \\
\text { practical } \\
\text { teaching }\end{array}$} & \multicolumn{4}{|c|}{ Assessment indexes for practical teaching } & \multirow{2}{*}{ Scores } \\
\cline { 3 - 7 } & Background & Input & $\begin{array}{c}\text { Teaching } \\
\text { Process }\end{array}$ & $\begin{array}{c}\text { Teaching } \\
\text { achievements }\end{array}$ & \\
\hline 1 & Background & 3 & 1 & 1 & 2 & 4 \\
\hline 2 & Input & 3 & 2 & 2 & 3 & 8 \\
\hline 3 & $\begin{array}{c}\text { Teaching } \\
\text { Process }\end{array}$ & 3 & 1 & 1 & 2 & 8 \\
\hline 4 & $\begin{array}{c}\text { Teaching } \\
\text { achievements }\end{array}$ & 2 & & & 4 \\
\hline
\end{tabular}

The weights of the indexes are determined in the following steps:

1) The assessment team is organized by inviting 9 experts who have been engaged in practical teaching and theoretical research for more than 5 years.

2) The table for assessing the weighting factors of first grade indexes in the evaluation (Table 1) is formulated.

3) The experts fill in the assessment table of weighting factors.

The experts compare the factors in each column and row to mark scores for the indexes adopting the four-point system. The extremely important, very important, important, less important, and unimportant indexes are marked with 4, 3, 2, 1, and 0 scores, respectively. Each expert fills in a copy of the table.

4) The assessment table of weighting factors filled by the experts is analyzed and the scores are converted to weights. After adjustment according to the calculated weights of the first grade indexes, the judgment table of weighting factors (Table 2) for establishing the evaluation system for teaching quality of HVCs in Chongqing is constructed.

In the evaluation system of practical teaching quality of HVCs, the first grade indexes include the background, input, process, and achievements of the practical teaching. The weights of these indexes are $15 \%, 30 \%, 30 \%$, and $25 \%$, respectively. 
Table 2 The judgment of weighting factors

\begin{tabular}{|c|c|c|c|c|c|}
\hline \multirow{2}{*}{$\begin{array}{l}\text { Indexes } \\
\text { Experts } \\
\text { Number }\end{array}$} & Index & Index & Index & Index & \multirow[b]{2}{*}{ Sum } \\
\hline & $\begin{array}{l}\text { Background for } \\
\text { practical teaching }\end{array}$ & $\begin{array}{l}\text { Input for practical } \\
\text { teaching }\end{array}$ & $\begin{array}{c}\text { Process for } \\
\text { practical teaching }\end{array}$ & Achievements & \\
\hline Expert 1 & 3 & 6 & 8 & 7 & 24 \\
\hline Expert 2 & 5 & 7 & 6 & 6 & 24 \\
\hline Expert 3 & 4 & 8 & 7 & 5 & 24 \\
\hline Expert 4 & 3 & 7 & 7 & 7 & 24 \\
\hline Expert 5 & 4 & 8 & 8 & 4 & 24 \\
\hline Expert 6 & 3 & 5 & 9 & 7 & 24 \\
\hline Expert 7 & 4 & 6 & 7 & 7 & 24 \\
\hline Expert 8 & 3 & 8 & 7 & 6 & 24 \\
\hline Expert 9 & 3 & 8 & 6 & 7 & 24 \\
\hline Total & 32 & 63 & 65 & 56 & 216 \\
\hline Average & 3.56 & 7.00 & 7.22 & 6.22 & 24 \\
\hline Weights & 0.148 & 0.292 & 0.301 & 0.259 & 1 \\
\hline $\begin{array}{l}\text { Adjusted } \\
\text { weights }\end{array}$ & 0.15 & 0.30 & 0.30 & 0.25 & 1 \\
\hline
\end{tabular}

\section{Conclusion}

Practical teaching is an important part in HVE teaching system. Studying and improving the evaluation system for practical teaching is a hot and key point in the reform of quality management of HVE, as well as a difficult issue of HVE. The evaluation system of practical teaching quality contains various contents and comprises of multiple subsystems. Therefore, the evaluation system needs to be established with the consideration of comprehensive factors, and the evaluation indexes require to be designed according to the practical situation of each college. In addition, the evaluation system needs to be assessed based on specific links in practical teaching to integrate various factors into a comprehensive system. By dosing so, it is expected to design a scientific and perfect index system for the evaluation system of practical teaching. Only constructing a scientific and correct control system for teaching quality and implementing it in the whole teaching process, the teaching quality can be improved in reality. As the factors influencing teaching quality are dynamic, not all the influencing factors can be included in the evaluation factors. Moreover, people have different opinions on the evaluation factors in different environments and conditions. Different HVCs are likely to hold different views of point on the weights of indexes as well. Considering these factors, the method how to more comprehensively, objectively, and scientifically assess practical teaching quality needs to be investigated further.

\section{Acknowledgement}

The work was supported by Chongqing education committee. (NO: 133312)

\section{References}

[1] Hua Xianghong, Zou Jingui, et al., Construction of practice teaching quality monitoring and evolution system in vocational education, Surveying and Mapping Engineering, Dec 2005,vol. 14, no. 4: 71-74.

[2] Chen Hong, Construction and application of colledge practice teaching quality evolution model, Research and Exploration in Laboratory, Jun 200, vol. 28, no. 6: 159.

[3] Zhao Xianmei, System for the practice teaching quality of higher vocational college, Journal of Guangdong Polytechnic Normal University, 2009, no.1: 74-77. 
[4] Du Xiangpei, Study and practice of establishing and perfecting education quality monitor system in higher institutions, Higher Agricultural Education, 2003, (9): 23-26.

[5] Zhang Weizhong, Zhang Xingwang, et al., Construction of the index system of evaluating the quality of practice teaching, Journal of Nanchang Institute of Technology, Apr 2008, Vo. 27, no. 2: 62-64. 